\title{
Recurrent Dystrophic Calcification of the Prostatic Resection Cavity After Transurethral Resection of the Prostate: Clinical Presentation and Endoscopic Management
}

\author{
Valentin Zumstein, MD,' Patrick Betschart, MD, Gautier Müllhaupt, MD, \\ Wolfram Jochum, MD, ${ }^{2}$ Hans-Peter Schmid, MD, ${ }^{1}$ and Dominik Abt, MD ${ }^{1}$
}

\begin{abstract}
Background: Dystrophic calcification (DC) can occur as a reaction to tissue damage and necrosis. So far, this has never been described as a complication after conventional transurethral resection of the prostate (TURP). Case Presentation: We report on a 59-year-old man who underwent uncomplicated monopolar TURP for lower urinary tract symptoms caused by benign prostatic hyperplasia. The patient showed an excellent course up to 5 weeks after the initial operation. Afterward he suffered from a rapid onset of irritative and obstructive voiding symptoms and pain. Complete DC of the prostatic resection cavity was found by cystoscopy and recurred quickly twice after Re-TURP despite anti-inflammatory treatment and normal urinary and metabolic findings. Complete recovery was only achieved by gently scraping off the calcifications avoiding further trauma to the residual prostatic tissue.

Conclusion: In rare cases, delayed occurrence of irritative and obstructive voiding symptoms after TURP can be caused by DC of the prostatic resection cavity and might be misinterpreted as post-TURP infection. The pathomechanism of DC and the presented case suggest minimizing tissue trauma by cautious removal of calcifications rather than performing extensive Re-TURP.
\end{abstract}

Keywords: dystrophic calcification, TURP, benign prostatic hyperplasia, BPH, lower urinary tract symptoms, LUTS, complication, morbidity

\section{Introduction and Background}

D ESPITE CONTINUED DEVELOPMENT of alternative resection-, ablation-, vaporization-, and enucleation techniques, conventional transurethral resection of the prostate (TURP) is still recommended as the gold standard for the surgical treatment of patients with a prostate size of 30 to $80 \mathrm{~mL}$ suffering from lower urinary tract symptoms (LUTS) caused by benign prostatic hyperplasia. ${ }^{1}$

Dystrophic calcification (DC) is defined as an inappropriate mineralization occurring in various tissues. Deposits are usually composed of calcium phosphate salts, including hydroxyapatite, but can also consist of other minerals known from urinary tract calculi. ${ }^{2}$ Though DC can occur in every type of tissue as a result of aging, tissue injury, and necrosis, it appears that muscles, tendons, skin, kidneys, and arteries are most prone to develop this disorder.

A total of four patients who developed DC after potassiumtitanyl-phosphate (KTP) laser ablation of the prostate have been described within two reports. ${ }^{3,4}$ Occurrence of extensive coagulation necrosis was suspected as underlying mechanism in these cases. Although complications associated with conventional TURP have been extensively assessed during the last decades, ${ }^{5,6} \mathrm{DC}$ of the prostatic resection cavity after TURP, to the best of our knowledge, has never been reported before.

\footnotetext{
${ }^{1}$ Department of Urology, Kantonsspital St. Gallen, St. Gallen, Switzerland

${ }^{2}$ Institute of Pathology, Kantonsspital St. Gallen, St. Gallen, Switzerland.
}

(C) Valentin Zumstein et al. 2017; Published by Mary Ann Liebert, Inc. This is an Open Access article distributed under the terms of the Creative Commons Attribution License, which permits unrestricted use, distribution, and reproduction in any medium, provided the original work is properly cited. 
The patient was discharged on time and showed an excellent course initially: IPSS: 6, QoL: 2, Qmax: $38 \mathrm{~mL} / \mathrm{s}$, PVR $0 \mathrm{~mL}$. Five weeks after the surgical procedure, irritative and obstructive voiding symptoms and motion/voidingdependent pain occurred. Cystoscopy was performed after failed combined analgesic, antibiotic, and antimuscarinic treatment and revealed complete calcification of the prostatic resection cavity (Fig. 1). Re-TURP was performed to remove calcifications. After a fast recurrence of symptoms and calcifications, remaining prostatic tissue was resected to capsular level. Histological analysis showed prostatic tissue with areas of necrosis with neutrophils and DCs (Fig. 2). Chemical analysis of the calcifications revealed hydroxyapatite and calcium phosphate.

During the whole treatment, urinary tract infections could be excluded and 24 hours urine collections and metabolic examinations revealed no pathological findings (normal daily hydration, no renal tubular acidosis or hyperparathyroidism, absence of lithogenic risk factors, high amounts of citrate in urine as a protective factor). Anti-inflammatory treatment using NSAIDs was performed after all reinterventions.

After the second relapse of symptoms and calcifications 2 weeks after complete TURP (performed 3 months after the initial operation), recovery time was extended to 8 weeks.

As symptoms persisted, we decided to perform further removal of calcifications with minimized tissue trauma by cautious removal of calcifications (no electricity used) rather than performing another resection. Pain subsided immediately after the first procedure performed in this way. Minimal residual calcifications were removed during a final intervention performed 6 weeks later (Fig. 3). Intradetrusor botulinum neurotoxin type A injection (100 U) was performed at the same time to accelerate recovery from urinary urgency and to allow for faster occupational reintegration and resulted in complete recovery with symptom-free micturition. Recurrence of calcifications could be excluded by ultrasound and cystoscopy during the following controls.

\section{Discussion and Literature Review}

Reoperation following TURP is necessary in about $2.6 \%$ after a mean follow-up of 16 months. ${ }^{8}$ Although DC is known to occur in inflamed, degenerated, or necrotic tissues, ${ }^{9}$ it has never been described after conventional TURP to the best of our knowledge. Our literature search revealed only four cases of DC after KTP laser vaporization of the prostate ${ }^{3,4}$ and one after cryotherapy for prostate cancer. ${ }^{9}$ Extensive necrosis was suspected as underlying cause in these cases.
FIG. 2. Histological analysis of prostatic tissue obtained during re-TURP revealed areas of necrosis and granular calcifications associated with necrotic acinar epithelium. (A) Hematoxylin and eosin staining, (B) Von Kossa staining. Original magnification $200 \times$.
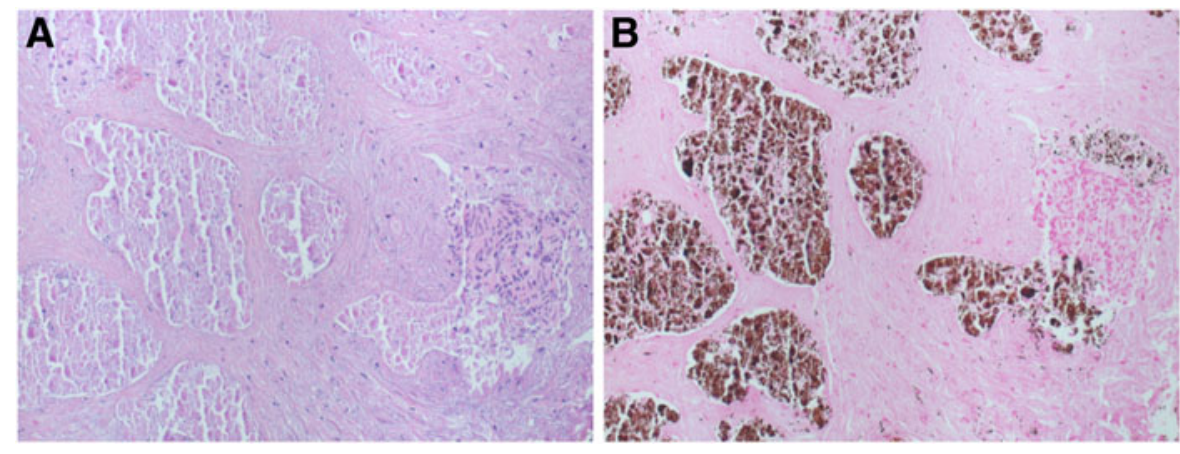


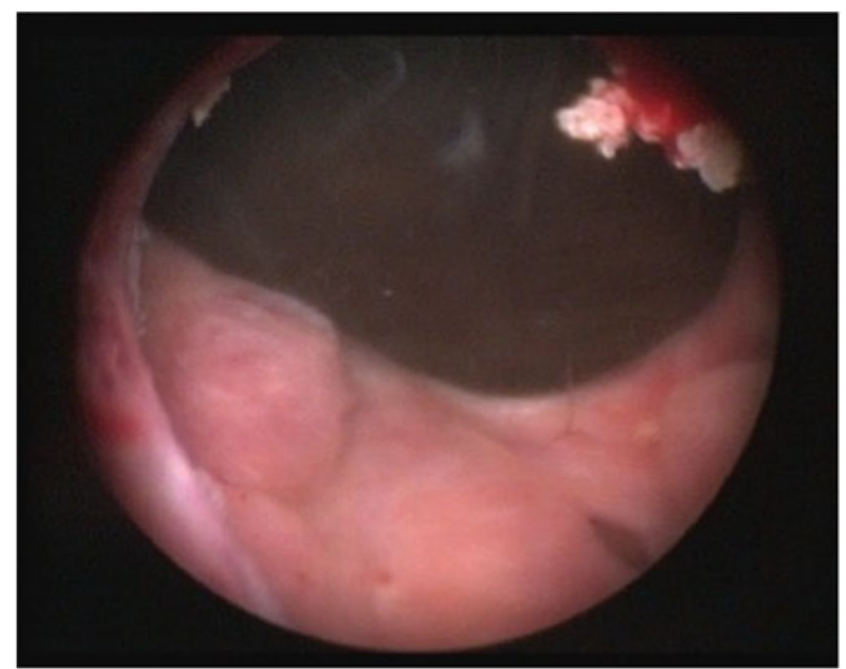

FIG. 3. Minimal residual calcifications only were found after minimizing tissue trauma for DC removal. DC =dystrophic calcification.

Our patient had no history of impaired wound healing. Metabolic evaluation including 24 hours-urinary analyses and urine cultures revealed no risk factors for DC. Moreover, coagulation was performed carefully during all interventions. Thus, the reason for recurrent occurrence of DC in this patient remains unclear.

In general, DC occurs independently from serum calcium and phosphate levels, though elevation of these ions might represent a risk factor. ${ }^{10}$ The pathogenesis of DC is characterized by an initial tissue injury leading to leakage of calcium by damaged cell membranes. The acidic environment of necrotic tissue further supports the process of saturation and crystallization. $^{2}$

After completed wound healing, this vicious circle is interrupted and no further calcification should occur. In accordance with that, calcifications disappeared in our patient after changing the treatment approach from resection to cautious removal of calcifications to avoid further trauma. However, calcifications were more pronounced during the first reinterventions and would have been hardly removable without performance of Re-TURP at his time.

\section{Conclusion}

Delayed occurrence of irritative and obstructive voiding symptoms after TURP can be caused by DC of the prostatic resection cavity in rare cases and might be misinterpreted as post-TURP infection. The pathomechanisms of DC and the presented case suggest minimizing tissue trauma by cautious removal of calcifications rather than performing extensive Re-TURP whenever possible.

\section{Disclosure Statement}

No competing financial interests exist.

\section{References}

1. Gratzke C, Bachmann A, Descazeaud A, et al. EAU guidelines on the assessment of non-neurogenic male lower urinary tract symptoms including benign prostatic obstruction. Eur Urol 2015;67:1099-1109.

2. Giachelli CM. Ectopic calcification: Gathering hard facts about soft tissue mineralization. Am J Pathol 1999;154:671-675.

3. Jeon SW, Park YK, Chang SG. Dystrophic calcification and stone formation on the entire bladder neck after potassiumtitanyl phosphate laser vaporization for the prostate: A case report. J Korean Med Sci 2009;24:741-743.

4. Tasci AI, Tugcu V, Ozbay B, Mutlu B, Cicekler O. Stone formation in prostatic urethra after potassium-titanylphosphate laser ablation of the prostate for benign prostatic hyperplasia. J Endourol 2009;23:1879-1881.

5. Rassweiler J, Teber D, Kuntz R, Hofmann R. Complications of transurethral resection of the prostate (TURP) incidence, management, and prevention. Eur Urol 2006;50: 969-979; discussion 980.

6. Reich O, Gratzke C, Bachmann A, et al. Morbidity, mortality and early outcome of transurethral resection of the prostate: A prospective multicenter evaluation of 10,654 patients. J Urol 2008;180:246-249.

7. Abt D, Mordasini L, Hechelhammer L, Kessler TM, Schmid HP, Engeler DS. Prostatic artery embolization versus conventional TUR-P in the treatment of benign prostatic hyperplasia: Protocol for a prospective randomized noninferiority trial. BMC Urol 2014;14:94.

8. Madersbacher S, Marberger M. Is transurethral resection of the prostate still justified? BJU Int 1999;83:227-237.

9. Dru C, Bender L. Dystrophic calcification of the prostate after cryotherapy. Case Rep Urol 2014;2014:471385.

10. Demetriou ET, Pietras SM, Holick MF. Hypercalcemia and soft tissue calcification owing to sarcoidosis: The sunlightcola connection. J Bone Miner Res 2010;25:1695-1699.

Address correspondence to: Valentin Zumstein, MD Department of Urology Kantonsspital St. Gallen Rorschacherstrasse 95 St. Gallen 9007 Switzerland

E-mail: valentin.zumstein@kssg.ch

$\begin{aligned} & \text { Abbreviations Used } \\ \text { DC } & =\text { dystrophic calcification } \\ \text { IPSS } & =\text { International Prostate Symptom Score } \\ \text { KTP } & =\text { potassium-titanyl-phosphate } \\ \text { LUTS } & =\text { lower urinary tract symptoms } \\ \text { PVR } & =\text { postvoid residual urine } \\ \text { TURP } & =\text { transurethral resection of the prostate }\end{aligned}$

Cite this article as: Zumstein V, Betschart P, Müllhaupt G, Jochum W, Schmid HP, Abt D (2017) Recurrent dystrophic calcification of the prostatic resection cavity after transurethral resection of the prostate: clinical presentation and endoscopic management, Journal of Endourology Case Reports 3:1, 81-83, DOI: 10.1089/ cren.2017.0058. 